\title{
Are patients aware of the risk of agranulocytosis when taking antithyroid drugs?
}

\section{Vincent Chau, Julie Andrew, Emma Ward, Ramzi Ajjan \& Robert Murray}

Department of Endocrinology, The Leeds Teaching Hospitals NHS Trust, Leeds, UK

\section{Introduction}

Hyperthyroidism affects $1.3 \%$ of the population. The antithyroid drugs (ATD), carbimazole and propylthiouracil, can induce agranulocytosis, a rare but potentially life threatening side-effect with a prevalence of $0.10-0.15 \%$. We assessed the adequacy of our patient's knowledge of this side-effect.

\section{Methods}

Patients on ATD completed a questionnaire before attending clinic. The questionnaire consisted of 9 questions detailing information they had received and knowledge of how they should respond if they become unwell on ATD. Data were collected over a 3 week period.

If you received written information was it understandable?

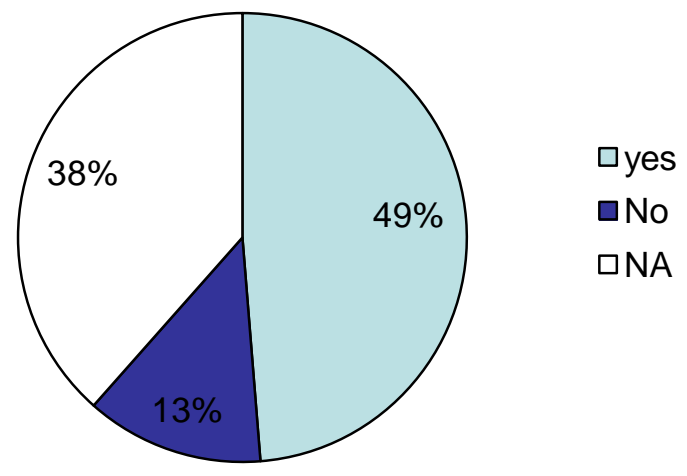

Figure 1: Patients' understanding of written information given.

What would you do with your ATD if you developed a severe sore throat?

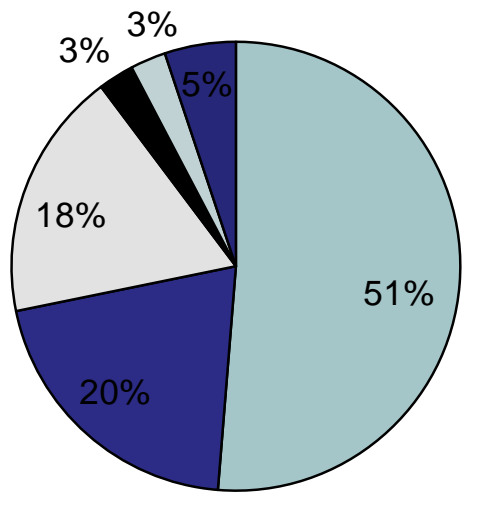

口Stop

- Continue

$\square$ Medical advise

Endocrine advise

$\square$ Not sure

-NA

\section{Results}

39 patients completed the questionnaire. 30 patients $(77 \%)$ said they received information regarding side-effects when ATD were commenced; 8 patients (21\%) said they did not; and 1 patient $(3 \%)$ was unsure. Most information was given verbally (32), and others include letters (11), cards (9) and leaflets (1). Only 19 patients (49\%) said the information given was understandable (Fig.1). Most patients had not experienced side-effects (18). The most common side-effects reported were sore throat (8), lethargy, and malaise (6). When asked what they would do in the event of a sore throat, most patients (62\%) said they will see their GP or attend $A+E$. Only 7 patients $(18 \%)$ knew that they needed a blood test. Most patients said they would obtain medical input immediately $(36 \%)$ or same day (36\%). Only 20 patients $(51 \%)$ said they would stop ATD in the event of a sore throat (Fig.2), and 18 patients (46\%) knew to restart ATD if blood test was normal.

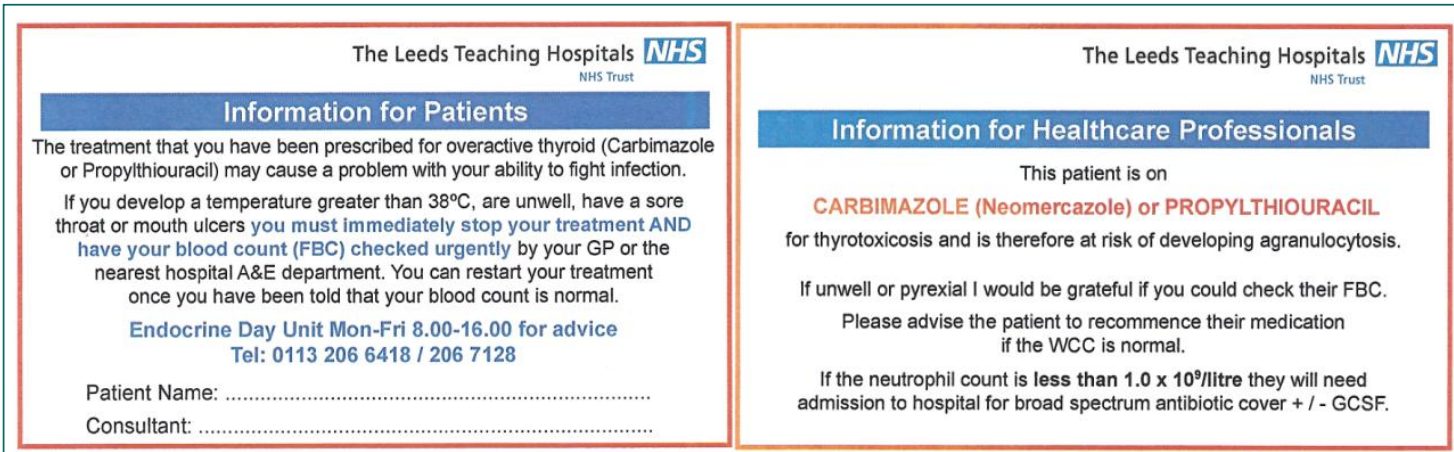

Figure 3: Front and back of the new ATD information card for patients.

\section{Conclusion}

This audit shows inadequate patient awareness of the potential life threatening side-effect of ATD. We have since introduced a credit card sized ATD information card (Fig.3) for patients commencing ATD. It provides instructions for patients and healthcare professionals to follow when infections occur. We aim to re-audit 12 months after introduction of this new card to assess the impact. 